\title{
Endoscopic appearance of sclerosing mesenteritis in the colon
}

A 46-year-old man presented with a 1month history of back pain, vague abdominal discomfort in the lower quadrants, change of bowel habit with constipation alternating with liquid, nonbloody stools, and a suprapubic mass about the size of his fist that he had noticed 1 week previously. Physical examination showed a suprapubic mass of $6-8 \mathrm{~cm}$, which was tender on deep palpation. A computed tomography (CT) scan showed a thickening of the sigmoid and descending colonic wall with increased opacification of the adjacent mesentery. Colonoscopy showed an edematous mucosa with pseudonodular areas and a total absence of normal motility in the rectum, sigmoid and descending colon ( $\bullet$ Fig. 1 ), with a normal appearing colonic mucosa proximal to the splenic flexure. Multiple biopsies were performed, which showed congestion and an inflammatory infiltrate, insufficient for a definite diagnosis.

By this time, the patient had become very sick with profuse diarrhea and had lost approximately $10 \mathrm{~kg}$ ( $12 \%$ of his usual body weight), so we decided to perform an exploratory laparotomy. An unresectable, fibrotic mass adherent to the retroperitoneum was found. Multiple biopsies were performed, which showed extensive areas of steatonecrosis with foci of lipidladen histiocytes, some fibrosis, and a mixed inflammatory infiltrate. A diagnosis of sclerosing mesenteritis was made and the patient was started on prednisolone $40 \mathrm{mg} /$ day and azathioprine $50 \mathrm{mg} /$ day, to which he responded promptly. At 1 year, both his CT scan and colonoscopy ( $\bullet$ Fig.2) were considered normal.

Sclerosing mesenteritis most commonly affects the small-bowel mesentery [1]. This probably contributes to the fact that most gastroenterologists are not familiar with the endoscopic changes characteristic of this disease. The reporting of this case should contribute to a greater awareness of this rare disease amongst gastrointestinal endoscopists, especially with regard to the endoscopic findings when the mesocolon is affected $[2,3]$.

Endoscopy_UCTN_Code_CCL_1AD_2AJ

Competing interests: None

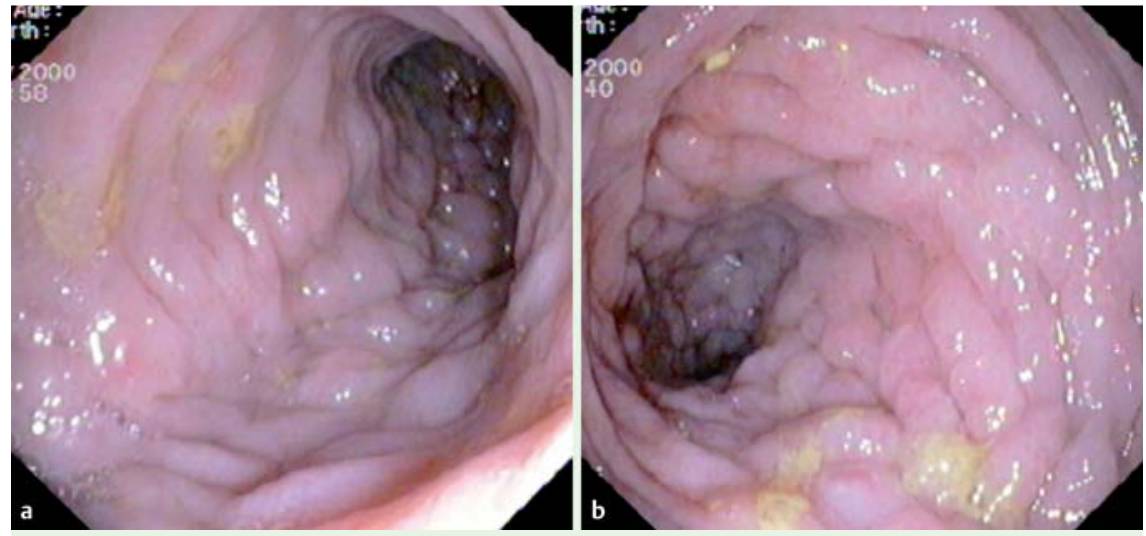

Fig. 1 Endoscopic images of the colonic mucosa at the time of diagnosis showing: a an edematous, congested mucosa; and $\mathbf{b}$ a pseudonodular mucosa, with absence of the normal vascular pattern but no evidence of ulceration.
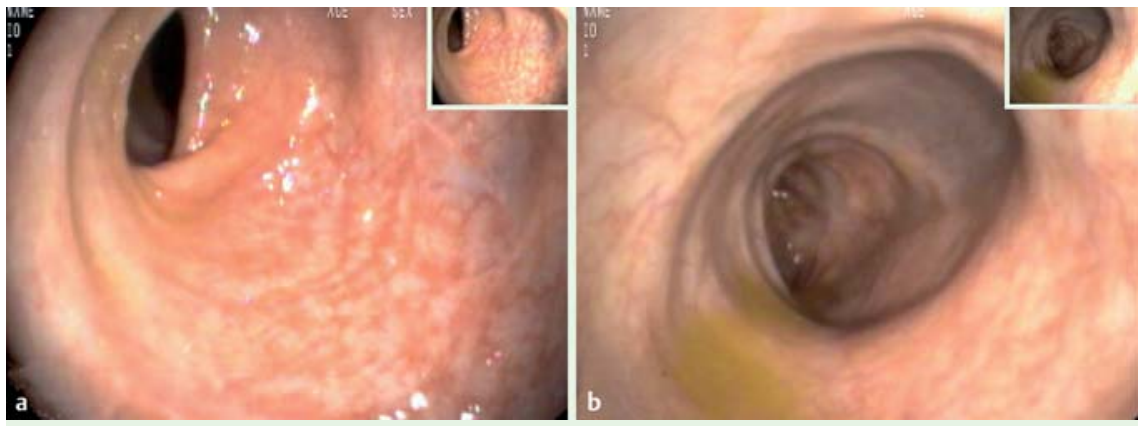

Fig.2 Endoscopic images of the colonic mucosa after 1 year of immunosuppressive therapy showing: $\mathbf{a}$ areas of slight erythema and hypervascularity; $\mathbf{b}$ otherwise greatly improved appearance as compared to the first examination.

\section{Cravo' ${ }^{1}$, P. Sousa ${ }^{1}$, I. Tavora ${ }^{2}$ N. Zozimo ${ }^{1}$, J. Velosa ${ }^{1}$}

${ }^{1}$ Department of Gastroenterology, Hospital de Santa Maria, Lisbon, Portugal

2 Department of Radiology, Hospital de Santa Maria, Lisbon, Portugal

\section{References}

1 Akram S, Pardi DS, Schaffner JA et al. Sclerosing mesenteritis: clinical features, treatment and outcome in ninety-two patients. Clin Gastroenterol Hepatol 2007; 5: 589 596

2 Adachi $Y$, Mori M, Enjoji $M$ et al. Mesenteric panniculitis of the colon. Review of the literature and report of two cases. Dis Colon Rectum 1987; 30: 962 -966

3 Popkharitov AI, Chomov GN. Mesenteric panniculitis of the sigmoid colon: a case report and review of the literature. J Med Case Reports $2007 ; 1: 108$

\section{Bibliography}

DOI http://dx.doi.org/

10.1055/s-0031-1291563

Endoscopy 2012; 44: E60

(c) Georg Thieme Verlag KC

Stuttgart · New York

ISSN 0013-726X

\section{Corresponding author}

\section{Cravo, MD}

Hospital de Santa Maria - Gastroenterology Rua Professor Egas Moniz

Lisbon 1100

Portugal

Fax: +351-21-7229850

marilia.cravo@sapo.pt 